\title{
Copper removal from industrial wastewaters by means of electrostatic shielding driven electrodeionization
}

\author{
K. Dermentzis ${ }^{1, *}$, A. Davidis ${ }^{1}$, D. Papadopoulou ${ }^{1}$, A. Christoforidis ${ }^{2}$, K. Ouzounis ${ }^{3}$ \\ ${ }^{I}$ Department of Engineering Science, Laboratory of Chemical Technology and Electrochemistry, \\ ${ }^{2}$ Department of Petroleum Technology, Laboratory of Environmental Protection, University of Kavala, Institute of Technology, \\ 65404, Agios Loucas, Kavala, Greece. \\ ${ }^{3}$ Department of Environmental Engineering, Laboratory of Environmental Chemistry, Democritus University of Thrace 67100 Xanthi, Greece.
}

Received 14 May 2009; Revised 14 October 2009; Accepted 2 November 2009

\begin{abstract}
Electrostatic shielding zones made of electrode graphite powder were used as a new type of ionic and electronic current sinks. Because of the local elimination of the applied electric field, voltage and current within the zones, ions are led inside them and accumulate there. We implemented the current sinks in electrodialysis of a simulated copper plating rinse water containing $100 \mathrm{mg} \mathrm{L}^{-1} \mathrm{Cu}^{2+}$ ions and electrodeionization of a $0.001 \mathrm{M} \mathrm{CuSO}_{4}$ solution with simultaneous electrochemical regeneration of the used ion exchange resin beds and obtained pure water with a $\mathrm{Cu}^{2+}$ ion concentration of less than $0.12 \mathrm{mg}$ $\mathrm{L}^{-1}$ at a flow rate of $1.29 \times 10^{-4} \mathrm{~L} \mathrm{~s}^{-1}$ diluate stream and a current density of $2 \mathrm{~mA} \mathrm{~cm}{ }^{-2}$.
\end{abstract}

Keywords: Copper removal, water reuse, faraday cage, membrane-less electrodialysis, continuous capacitive deionization.

\section{Introduction}

Copper is a persistent, bio-accumulative and toxic heavy metal which does not break down in the environment, is not easily metabolized and can harm human health. Waste streams from copper electroplating industries, textile industries or washing effluents for remediation of soil contaminated with copper may contain up to $500 \mathrm{mg} \mathrm{L}^{-1}$ copper, which, according to environmental regulations worldwide must be controlled to an acceptable level before being discharged to the environment. Only $30-40 \%$ of all metals used in plating processes are effectively utilized i.e. plated on the articles while the rest contaminates the rinse waters during the plating process when the plated objects are rinsed upon removal from the plating bath.

Several treatment processes have been suggested for the removal of copper from aqueous waste streams, such as adsorption on activated charcoal [1], biosorption on marine algae [2], ion exchange on zeolites [3], ion exchange on chelating resins [4,5], flotation-microfiltration [6] and chemical precipitation [7,8].

Although chemical precipitation is the most economic and the most commonly utilized procedure for the treatment of copper-bearing effluents, it can become ineffective in the presence of strong complexing agents $[9,10]$. In addition, the high buffer capacity provided by complexing agents requires excessive amounts of chemicals to neutralize alkalinity. The precipitated sludge con-

\footnotetext{
* E-mail address: demerz@otenet.gr ISSN: 1791-2377 (C) 2009 Kavala Institute of Technology. All rights reserved.
}

taining the concentrated $\mathrm{Cu}(\mathrm{OH})_{2}$ is an extremely hazardous waste and must be disposed of using special facilities at great expense to industry.

From the viewpoint of environmental protection and resource saving, effective recycling and reusing of the metal wastewater is strongly expected. Closed-recycle system or so-called effluentfree technology should be developed.

Electrochemical methods such as cathodic reduction and electrowinning [10-12], electrodialysis [13-16] and electrodeionization [17-19] have been recently developed to contribute to the solution of this serious environmental problem of toxic heavy metal removal.

Electrodeionization is the removal of ions and ionizable species from water or organic liquids. It uses electrically active media and an electrical potential to cause ion transport and may be operated batch wise, or continuously. Electrodeionization is an emerging environmental green technology of antipollution.

Continuous processes such as Electrodialysis, and Filled Cell Electrodialysis or otherwise called Continuous Electrodeionization comprise alternating permselective cation exchange membranes and anion exchange membranes, which under the influence of the electric field allow only cations or only anions respectively to permeate their mass and simultaneously retain coions so that diluate and concentrate compartments are created and deionization occurs.

Batch processes such as Capacitive Deionization [20,21] are 
collection / discharge processes which rely on the formation of double-layer supercapacitor at the solution/electrode interface and need electrodes with large specific areas such as nano-structured activated carbon aerogels.

In our previous works [22-25] we have shown that diluate and concentrate compartments and therefore electrodialysis and electrodeionization are feasible by using electrostatic shielding zones-ionic current sinks (ICSs) instead of permselective ion exchange membranes.

The present paper offers a new alternative way of a membrane-less process of electrodialysis and electrodeionization for removal of $\mathrm{Cu}^{2+}$ ions from industrial effluents e.g. copper plating rinse waters.

The proposed new electrodeionization process differs from classical electrodialysis-continuous electrodeionization processes in that it does not use any permselective ion exchange membranes and therefore it does not exhibit the membrane associated limitations such as concentration polarization and water dissociation. It also differs from classical batch wise operated capacitive deionization in that it is a continuous process i.e. diluate and concentrate are received from separate and unchanged compartments without any removal of diluate and concentrate or any down time for electrode saturation, regeneration and rinsing steps.

\section{Experimental \\ 2.1 Electrodes}

We used platinized titanium grids as end-electrodes in all our experiments.

The intermediate electrodes ICSs must be electronically and ionically conducting. They are packed beds of graphite powder (Merck, particle size $<50 \mu \mathrm{m}$, electrical conductivity $2 \times 10^{4} \mathrm{~S} \mathrm{~m}^{-2}$ ) or electrode graphite powder (fig. 1a,b and fig. 2) which is used as anode by the electrolytic production of aluminium (Aluminium of Greece, particle size $<1 \mathrm{~mm}$, electrical conductivity $3.3 \times 10^{4} \mathrm{~S}$ $\mathrm{m}^{-2}$ ). Anode graphite is preferable because of its better electrical and electrocatalytic properties. The ICS beds used for the electrodialysis experiments (fig. 1a,b) are $5 \mathrm{~mm}$ thick each, while the ICS beds used for the filled cell electrodeionization (fig.2), are thicker $(10 \mathrm{~mm})$. The graphite powder material is a known electronic conductor but not an ionic one itself. The packed bed electrode that is based on that but also contains water and ions is, as a whole, an electronically and ionically conducting ensemble instead.

\subsection{Electrodes}

The cell compartments are separated from each other by ion conducting ceramic or polymeric separators or cardboard sheets $\mathrm{S}$ which prevent intermixing of solutions without obstructing the migration of ions in the electric field. The separators should exhibit low zeta potentials to avoid aimless electroosmotic transport of purified water into the ion sinks (ICSs).

\subsection{Cells}

The self-made electrodialysis cell illustrated in fig. 1 contains four ICSs serving as ion traps and ion concentrating compartments,
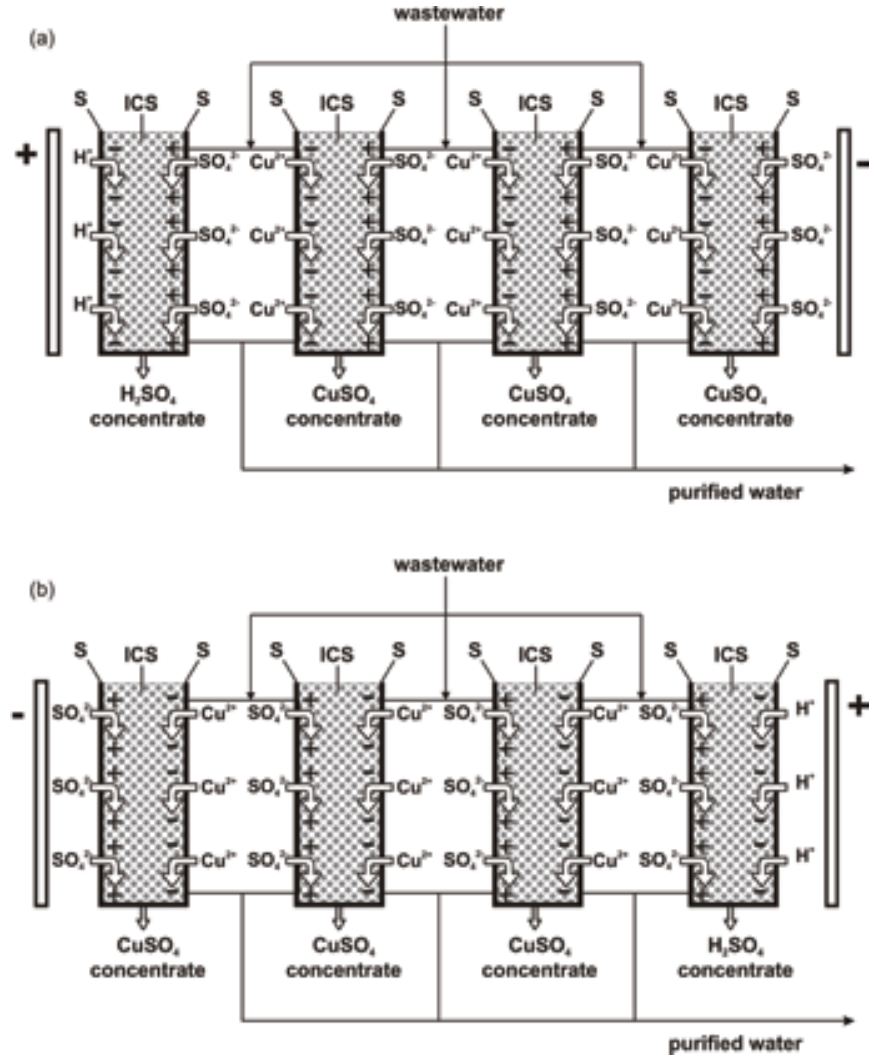

Figure 1(a). Schematic diagram for electrostatic shielding electrodialysis of copper bearing wastewaters. $\mathrm{Cu}^{2+}$ or $\mathrm{H}^{+}$cations and $\mathrm{SO}_{4}{ }^{2-}$ anions accumulate inside the electrostatically shielded ICSs, (b) the same cell by polarity reversal without any negative impact on the electrodialysis process. Only the direction of the entering ions is reversed.

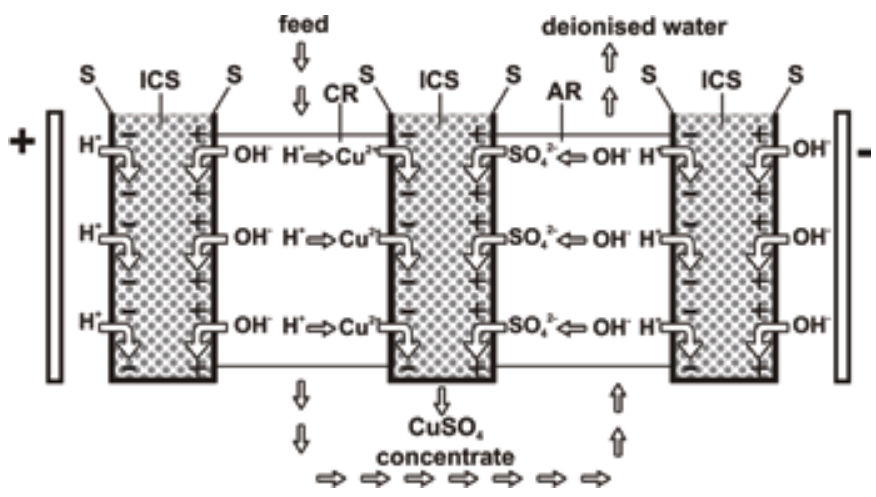

Figure 2. Schematic diagram of an electrostatic shielding electrodeionization cell for removal of $\mathrm{Cu}^{2+}$ ions with simultaneous regeneration of the ion exchange resin beds. The cell contains three ICSs, one CR loaded and one AR loaded diluate compartments. $\mathrm{Cu}^{2+}$ cations and $\mathrm{SO}_{4}{ }^{2-}$ anions accumulate inside the central ICS. Water to be deionized permeates first the $\mathrm{CR}$ and then the $\mathrm{AR}$ resin bed.

three diluate compartments between them and two electrode compartments, all placed in parallel. Each compartment is $7 \mathrm{~cm}$ in length and $8 \mathrm{~cm}$ in width. The ICSs have a thickness of $5 \mathrm{~mm}$ and an effective area of $50 \mathrm{~cm}^{2}$ each. The area of each ICS is equal to the vertical cross-section of the electrolytic cell. All compartments are separated from each other by the separators S. The distance between two successive ICSs and also between the ICS and the adjacent end-electrode is $5 \mathrm{~mm}$ and is determined by the ion conducting separators and spacers. 
The separators are sealed so that the different compartments do not communicate hydraulically with each other but only electrically (ionically) through the electric field. Each ICS has a bipolar function and belongs simultaneously to two adjacent diluate compartments as in bipolar electrochemical double layer supercapacitors.

The separators can be omitted in case porous conductive sheets, such as conductive ceramics, porous carbon paper or aerogel sheets, or other porous composite electrodes are used which can function both, as intermediate electrodes and separators as well.

The three diluate compartment are filled with the feed solution. The electrode compartments are filled with a $0.05 \mathrm{M} \mathrm{H}_{2} \mathrm{SO}_{4}$ solution, while the four concentrate compartments ICSs are only intermittently rinsed with the feed solution and are steadily let to drain. This pressure difference caused by the different water levels between the diluate compartments and the concentrate compartments ICSs prevents diffusional leakage of ions from the more concentrated ICS-solution into the adjacent diluted ones. Deionization in the diluate compartments can not be realized without keeping the water level inside the ICSs at lowest level. If the feed solution in the diluate compartments is soaked in a porous material, no pressure difference between the diluate and concentrate compartment exists. Deionization in the diluate compartment is realized without any pressure so long as the concentrate solution level is kept lowest by simply letting it to drain from the porous water permeable bottom of the ICS. Furthermore, the porous ionically and electronically conductive media of which the ICSs are made must cover uniformly all their space without allowing any ions to escape from the diluate compartments to the electrode compartments or in the opposite direction without passing through the ICS mass.

Fig. 2 shows the self-made electrodeionization cell consisted of seven separate, in parallel placed compartments: anode compartment, left ICS, cation exchange resin (CR) loaded compartment, central concentrate compartment (ICS), anion exchange resin (AR) loaded compartment, right ICS and cathode compartment. The compartments are separated from each other by the six ion conducting porous polypropylene separators $\mathrm{S}$ and are pressed together to form an assembly by using spacers and screws. Each compartment is $7 \mathrm{~cm}$ in length and $8 \mathrm{~cm}$ in width. The ICSs have a thickness of $5 \mathrm{~mm}$ and an effective area of $50 \mathrm{~cm}^{2}$. The area of each ICS is equal to the vertical cross-section of the electrolytic cell. The rest four compartments are $10 \mathrm{~mm}$ thick each.

The $\mathrm{CR}$ and $\mathrm{AR}$ resins were pretreated and immersed in a 0.1 $\mathrm{M} \mathrm{CuSO}_{4}$ and $0.1 \mathrm{M} \mathrm{Na}_{2} \mathrm{SO}_{4}$ solutions respectively for 3 days, then packed into the corresponding CR-loaded and AR-loaded compartment and rinsed with deionized water. The anode and the cathode compartments were filled with $0.05 \mathrm{M} \mathrm{H}_{2} \mathrm{SO}_{4}+0.05 \mathrm{M} \mathrm{Na}_{2} \mathrm{SO}_{4}$ and $0.05 \mathrm{M} \mathrm{NaOH}+0.05 \mathrm{M} \mathrm{Na}_{2} \mathrm{SO}_{4}$ solutions respectively.

The graphite powder was activated by treating it in a $1 \mathrm{M}$ $\mathrm{NaOH}$ solution at $90^{\circ} \mathrm{C}$ for three hours. To complete physical absorption of $\mathrm{CuSO}_{4}$ in graphite, the ICSs were rinsed with a 0.1 $\mathrm{M} \mathrm{CuSO}_{4}$ solution until saturation and then with deionized water. This initial curing of graphite powder with $\mathrm{Cu}^{2+}$ ions was for its physical adsorption to reach saturation and hence not be operative during the electrodeionization process.

Graphite powder used as ICS material is chemically and thermally very stable but electrochemically quite stable, because it starts to corrode when its relatively narrow potential window is exceeded. Thinner ICSs are more stable and can operate at increased current densities. Platinized or ruthenized graphite and activated carbon powder, platin spongue or other dimensionally stable electrodes are stable and suitable even at higher fields but are more expensive.

\subsection{Apparatus}

Atomic Absorption Spectroscopy AAS (Perkin Elmer 5100) was used to determine the $\mathrm{Cu}^{2+}$ ion concentrations in water. A power supply (PHYWE) was used to maintain constant DC voltage or constant DC current. Voltage and current were measured by a multimeter (PHYWE). Conductivities were measured by means of a conductometer (inoLab WTW). The temperature was held at 298 $\pm 3 \mathrm{~K}$ during all experiments.

\subsection{Chemicals}

$\mathrm{CuSO}_{4}, \mathrm{H}_{2} \mathrm{SO}_{4}$ and $\mathrm{Na}_{2} \mathrm{SO}_{4}$ were of analytical grade (Merck). The ion exchange resins used were strongly cation exchanger $\mathrm{H}^{+}$-form (Amberlite IR-120, Merck,) with an ion exchange capacity of 1.7 mmol ml-1 and strongly basic anion exchanger $\mathrm{OH}^{-}$-form (Merck) with an ion exchange capacity of $1.45 \mathrm{mmol} \mathrm{ml}^{-1}$.

\section{Results and discussion}

\subsection{Electrostatically shielded ion concentrating compart- ments - ESZs, ICSs and ECSs}

Current sinks and sources are local currents from a location where they can be detected into a location they can not be detected (current sink) or vice versa (current source). Current sinks and sources have particular relevance in current across biological membranes (neurobiology) and have proved to be valuable in the study of brain function [26]. Furthermore, current sinks are used in several electronic applications [27].

However, all known current sinks are related to electronic current sinks (ECSs). Our search throughout literature has not resulted in any other paper except for our previous works [22-25] dealing with ICSs. We created ICSs through electrostatic shielding by employing electronically and ionically conducting media e.g. graphite powder and used them as ion concentrating compartments in form of ESZs.

It is known from electric field theory and Faraday cage [28] and our previous works that, when a conductor is placed inside an electric field, an opposite field is formed so that the original electric field in the interior of the conductor is canceled. The field intensity inside the conductor is zero and its whole space is electrostatically shielded independent on the external field intensity. Therefore, an abrupt potential jump is formed between the inside and the outside of the conductor. Since in an electrolytic or an electrodialysis cell ion migration is caused by the applied electric field, it will stop within an electronically and ionically conducting ICS of zero field, interposed between the anode and cathode.

The ESZs become ion concentrating compartments while the adjacent compartments become ion diluting compartments. The ESZ acts here as a "sink" for ions and ionic currents (ICS). 
The ionic current (real direction) is eliminated at the cathodically polarized side of the ICS (current sink) and appears again at its anodically polarized side (current source). $\mathrm{Cu}^{2+}$ and $\mathrm{SO}_{4}{ }^{2-}$ ions can move inside the ICS but only by diffusion and convection and not in field direction.

The ion concentrating compartment ICS is never saturated with the accumulated ions. Because of the electric field its two short-circuited sides become polarized and saturated with oppositely charged ions but at the same time they are discharged and release the same ions because of shorting.

The ICS (electronic conductor) does not need practically any potential to carry the current through its mass. The relatively to electrolytic solutions high electronically conducting ICS not only does not bring about any additional potential drop in the cell but, on the countrary, it helps the current flowing the cell to increase by lowering the total resistance of the cell. The ICS consumes no electrical energy $\left(\mathrm{E}=\mathrm{U} \cdot \mathrm{I}=\mathrm{I}^{2} \bullet \mathrm{R}=0\right.$, since $\mathrm{U}_{I C S}=0$ or $\left.\mathrm{R}_{I C S}=0\right)$. In multi-cell stacks where a series of concentrate compartments (ICSs) and diluate compartments alternate, the unit cell comprises one diluate compartment and one ICS. The electrical energy is consumed for electromigration of ions only in the diluate compartment which is energetically very favorable.

Up to now, no other paper apart from our previous works, appeared in literature dealing with such ionic and electronic sinks. We can take advantage of these useful new findings and drive ions inside the ICSs, create ion concentrating and ion depleting compartments and perform in this way a membrane-less electrodialysis and electrodeionization of water and industrial effluents.

\subsection{Electrostatic shielding electrodialysis of copper ion bearing rinse waters}

Acid sulfate copper plating baths contain $\mathrm{CuSO}_{4}$ and $\mathrm{H}_{2} \mathrm{SO}_{4}$. We have prepared a simulated copper plating rinse water containing $396 \mathrm{mg} \mathrm{L}^{-1} \mathrm{CuSO}_{4} \cdot 5 \mathrm{H}_{2} \mathrm{O}\left(100 \mathrm{mg} \mathrm{L}^{-1} \mathrm{Cu}\right)$ which we acidified with $\mathrm{H}_{2} \mathrm{SO}_{4}$ until it reached $\mathrm{pH}=3$ and placed it in the three diluate compartments of the cell illustrated in fig. 1 for electrodialytic treatment. The proposed new electrostatic shielding electrodialysis cell with ICSs instead of ion exchange membranes has proved to be efficient also for the removal of heavy metal ions such as $\mathrm{Cu}^{2+}$. The obtained experimental results are listed in table 1 .

Table 1. Electrostatic shielding electrodialysis of a simulated copper plating rinse water without the assistance of ion exchange resin beds. (Solution volume $\mathrm{V}=150 \mathrm{ml}$, current density $\mathrm{i}=1.1-1.9 \mathrm{~mA} \mathrm{~cm}^{-2}$, voltage $\mathrm{U}=50 \mathrm{~V}$ )

\begin{tabular}{|c|c|c|c|}
\hline $\begin{array}{l}\text { time } \\
(\min .)\end{array}$ & $\begin{array}{c}\text { current } \\
(\mathrm{mA})\end{array}$ & $\begin{array}{c}\text { concentration } \\
\mathrm{Cu}^{2+}\left(\mathrm{mg} \mathrm{L}^{-1}\right)\end{array}$ & $\begin{array}{l}\text { removal } \\
\mathrm{Cu}^{2+}(\%)\end{array}$ \\
\hline 0 & 92 & 100.0 & - \\
\hline 5 & 79 & 80.8 & 19.1 \\
\hline 10 & 70 & 63.3 & 36.6 \\
\hline 15 & 61 & 57.5 & 42.5 \\
\hline 20 & 59 & 43.2 & 56.7 \\
\hline 25 & 57 & 31.5 & 68.4 \\
\hline 30 & 56 & 22.4 & 77.5 \\
\hline 35 & 55 & 15.7 & 84.2 \\
\hline
\end{tabular}

Fig.3 depicts the concentration variations and percent removal of $\mathrm{Cu}^{2+}$ ions versus time in the three diluting compartments. The process was conducted under constant voltage and decreasing current. The current is falling due to the fact that the process is controlled by ion migration and as the ionic content of the medium drops so does its conductivity, resulting in increased ohmic losses. $\mathrm{Cu}^{2+}$ cations in the diluate compartments permeate the ICSs and accumulate there. At higher fields where the decomposition potential of $\mathrm{CuSO}_{4}$ can be exceeded, $\mathrm{Cu}^{2+}$ ions can also partially be electronated and electrodeposited to pure metal at the cathodically polarized sides of the ICSs through charge transfer reactions [2325]. Both phenomena contribute to copper removal in the diluate compartments. The $\mathrm{Cu}^{2+}$ ion concentrate received from the bottom of the ICSs may either be recycled to the cathodic compartment to be electrodeposited as pure metal through electrowinning or be given back to the electrolytic copper bath for reuse. The produced pure water can be reused as rinsing water. In this way, the process can save a lot of water resource and realize "zero pollution".

Table 2. Electrostatic shielding electrodeionization of a $0.001 \mathrm{M}$ $\mathrm{CuSO}_{4}$ solution with the assistance of ion exchange resin beds. (Flow rate $\mathrm{q}=1.29 \times 10^{-4} \mathrm{~L} \mathrm{~s}^{-1}$, current density $\mathrm{i}=$ $\left.2 \mathrm{~mA} \mathrm{~cm}^{-2}\right)$.

\begin{tabular}{|c|c|c|}
\hline $\begin{array}{l}\text { time } \\
\text { (h) }\end{array}$ & $\begin{array}{c}\text { concentration } \\
\mathrm{Cu}^{2+}\left(\mathrm{mg} \mathrm{L}^{-1}\right)\end{array}$ & $\mathbf{p H}$ \\
\hline 0 & 0 & 7.0 \\
\hline 1 & 7 & 5.7 \\
\hline 2 & 18 & 4.7 \\
\hline 3 & 33 & 3.9 \\
\hline 4 & 90 & 3.5 \\
\hline 5 & 151 & 3.2 \\
\hline 6 & 246 & 3.0 \\
\hline 7 & 373 & 2.8 \\
\hline 8 & 478 & 2.7 \\
\hline 9 & 509 & 2.6 \\
\hline 10 & 527 & 2.5 \\
\hline
\end{tabular}

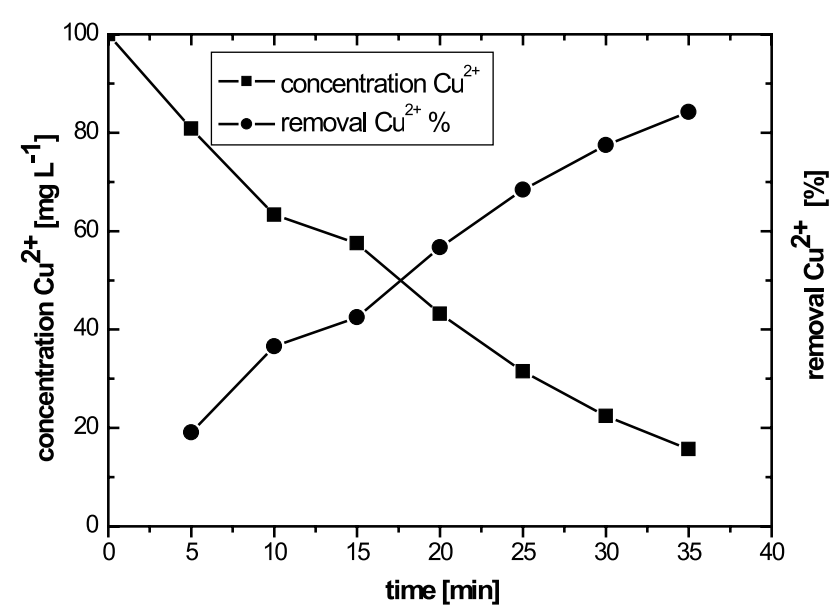

Figure 3. Concentration variation and \% removal of $\mathrm{Cu} 2+$ ions with time in the diluate compartments by the electrostatic shielding electrodialysis of copper plating rinse waters. 
The removal of $\mathrm{Cu}^{2+}$ ions is more effective when the electrodialysis cell is assisted by ion exchange resins as will be explained in section 3.3.

\subsection{Regeneration of ion exchange resins - electrodeioniza- tion of a $0.001 \mathrm{M} \mathrm{CuSO}_{4}$ solution}

High purity deionized water can be produced with the filled cell electrodeionization device (fig.2). Feed water must permeate first the $\mathrm{CR}$ and then the AR resin to be deionized.

We used a synthetic $0.001 \mathrm{M} \mathrm{CuSO}_{4}$ solution containing 63.5 $\mathrm{mg} \mathrm{L}{ }^{-1} \mathrm{Cu}$ and obtained pure water with a $\mathrm{Cu}^{2+}$ ion concentration of less than $0.12 \mathrm{mg} \mathrm{L}^{-1}$ in both modes, batch or continuous, while the resins are simultaneously regenerated without the use of any chemical regenerants. The product water quality stays constant over time, whereas in regenerable ion exchange with chemicals it degrades as the resins approach exhaustion.

$\mathrm{H}^{+}$and $\mathrm{OH}^{-}$ions are formed at the anode and cathode through the water splitting reactions:

$$
\begin{aligned}
& \mathrm{H}_{2} \mathrm{O} \rightarrow 2 \mathrm{H}^{+}+1 / 2 \mathrm{O}_{2}+2 \mathrm{e}^{-} \quad \text { (anode) } \\
& 2 \mathrm{H}_{2} \mathrm{O}+2 \mathrm{e}^{-} \rightarrow 2 \mathrm{OH}^{-}+\mathrm{H}_{2} \quad \text { (cathode) }
\end{aligned}
$$

The generated $\mathrm{H}^{+}$ions in the anode compartment and the anodically polarized side of the left ICS repel and replace the $\mathrm{Cu}^{2+}$ cations from the $\mathrm{CR}$ resin and the generated $\mathrm{OH}^{-}$ions in the cathode and the cathodically polarized side of the right ICS repel and replace the $\mathrm{SO}_{4}{ }^{2-}$ anions from the $\mathrm{AR}$ resin. The replaced cations and anions together with the electroosmotically transported water molecules are transferred to the central concentrate compartment (ICS) where, due to electrostatic shielding, the electromigration of ions is stopped and they accumulate there. The formed $\mathrm{CuSO}_{4}$ concentrate is let to drain from the bottom of the central ICS and is collected in a container placed underneath, in which about $100 \mathrm{ml}$ of deionized water was placed. Rinsing of the central ICS occurs intermittently with the collected $\mathrm{CuSO}_{4}$ concentrate solution itself.

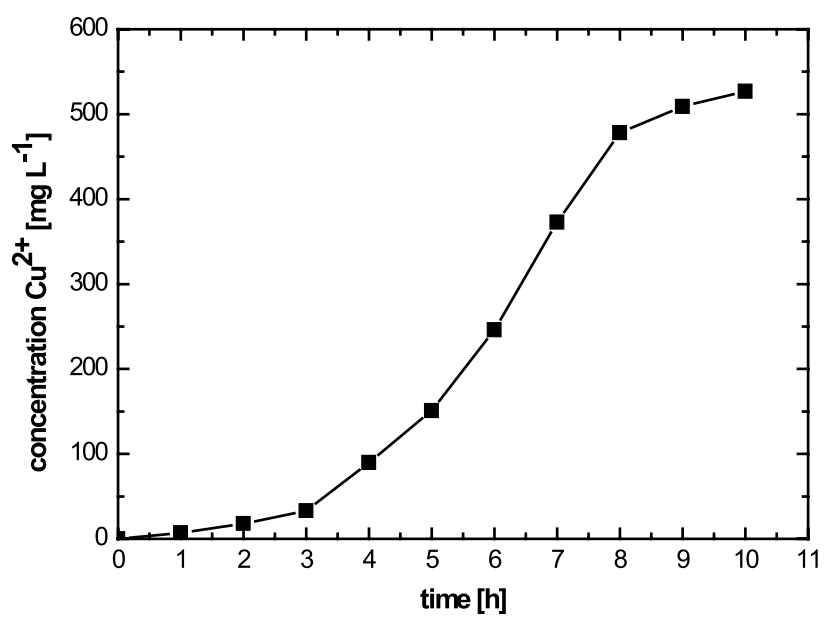

Figure 4. Concentration variation with time of $\mathrm{Cu}^{2+}$ ions in the central ICS during the electrostatic shielding electrodeionization of a $0.001 \mathrm{CuSO}_{4}$ solution.

The right and left ICSs do not at all contribute to electro- deionization but are essential. We have found that electrostatic shielding and therefore the capture of the incoming ions inside the central ICS is not so effective if the two outer ICSs are missing.

Precipitation of insoluble hydroxides (scaling) such as $\mathrm{Cu}(\mathrm{OH})_{2}$ inside the central ICS was not observed because this ICS compartment becomes gradually acidic. Part of the generated $\mathrm{H}^{+}$ions at the anodically polarized side of the left ICS migrate through the CR resin bed into the central concentrate compartment (ICS). Similarly, part of the $\mathrm{OH}^{-}$ions generated at the cathodically polarized side of the right ICS migrate through the AR resin bed and result in the same central concentrate compartment. It is well known that the migration rate of the $\mathrm{H}^{+}$ions is greater than that of the $\mathrm{OH}^{-}$ions. Therefore, $\mathrm{pH}$ inside the central ICS drops with time (fig.5).

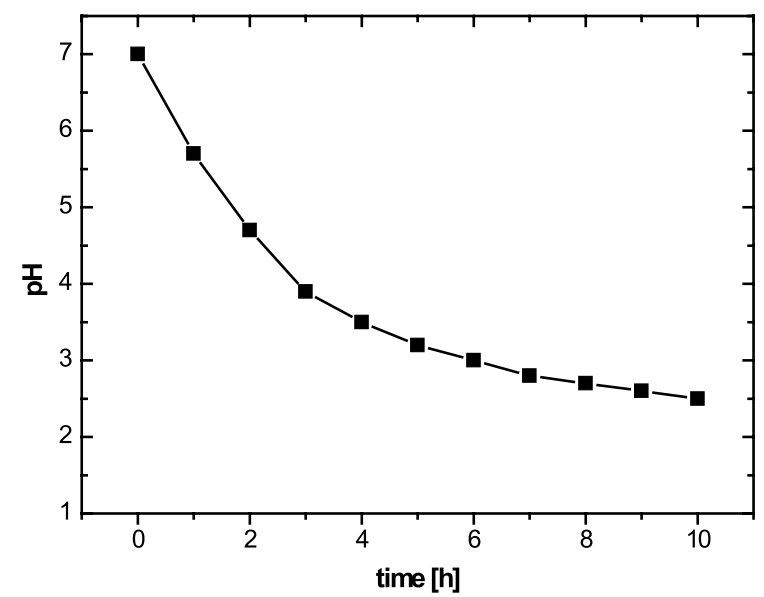

Figure 5. $\mathrm{pH}$ variation with time in the central ICS during the electrostatic shielding electrodeionization of a $0.001 \mathrm{M} \mathrm{CuSO}_{4}$ solution.

The electrodeionization performance was evaluated in terms of percent removal $(p r)$, current efficiency $(c e)$ and enrichment factor $(e f)$, which were calculated from the equations (1), (2) and (3) respectively:

$$
\begin{aligned}
& p r=\frac{C_{o}-C}{C_{o}} \times 100 \\
& c e=z \times F \times Q \times \frac{C_{o}-C}{I} \\
& e f=\frac{C_{c}}{C_{o}}
\end{aligned}
$$

where $\mathrm{C}_{\mathrm{o}}$ and $\mathrm{C}$ are the inlet and outlet concentrations of $\mathrm{Cu}^{2+}$ ions in the diluate compartments and $\mathrm{C}_{\mathrm{c}}$ in the concentrate compartment respectively (moles $\mathrm{L}^{-1}$ ), $\mathrm{z}$ the ion charge, $\mathrm{F}$ the faraday constant (96453 A s), Q the flow rate $\left(\mathrm{L} \mathrm{s}^{-1}\right)$, and I the current (A).

In the continuous mode with a flow rate of $1.29 \times 10^{-4} \mathrm{~L} \mathrm{~s}^{-1}$ diluate stream and a constant current density of $2 \mathrm{~mA} \mathrm{~cm}^{-2}$ the current efficiency for $\mathrm{Cu}^{2+}$ ion removal is $26 \%$. At higher current densities the removal of $\mathrm{Cu}^{2+}$ ions and therefore the current efficiency can be further increased. However, this additional increase 
is attributed to electrodeposition of the pure metal at the cathodically polarized side of the central ICS, due to exceeding the electrochemical decomposition potential of $\mathrm{CuSO}_{4}$ between the two polarized sides of the ICS.

The deionization process by means of the proposed selfmade electrodialysis and electrodeionization cells with the cardboard sheets as ion conducting separators and the relatively thick ion diluate compartments probably require an increased voltage and energy consumption. The bulk of the applied potential drops mainly on the separators and the diluate compartments. Consequently, the power requirements of the process per $\mathrm{L}$ of treated effluent is relatively high. The applied voltage $U$ for the electrodialysis and electrodeionization processes were 50 and 45 Volt respectively and the corresponding electrical energy consumptions $E$ calculated from the equation $E=U \cdot I \cdot t$ were 13.12 and $9.7 \mathrm{wh}$ $\mathrm{L}^{-1}$ of treated effluent. It is obvious that thinner low-resistance separators and diluate compartments must be used in order to achieve lower power requirements.

\section{Conclusions}

The proposed new cells with electrostatically shielded zones-ionic current sinks instead of permeselective ion exchange membranes can find several electrochemical-technological applications of antipollution. The proposed processes seem promising and advantageous over the existing classical membrane technologies regarding concentration polarization and membrane fouling. They need further investigation to be developed into innovative and competitive electrochemical processes for water electrodialysis and electrodeionization.

Especially in electrodialysis applications, the thick, self-made and energy consuming graphite powder-separator beds which are used as electrostatically shielded zones-ion current sinks should be replaced with thinner porous composite ceramic or polymeric intermediate electrode sheets to substantially increase the current density and desalting rate and simultaneously lower the electrical energy consumption. Furthermore, multi-cells with alternating thin diluate and concentrate compartments should be constructed in order to minimize the share of the voltage drop on the two endelectrodes so that the applied cell voltage and the electrical energy is used effectively and almost exclusively for electromigration of ions in the diluate compartments.

Research is needed to gain more information about the implementation possibilities of the proposed ionic current sinks and their dynamics to contribute to the solution of environmental or other technological tasks.

\section{References}

1. L. Monser, N. Adhoum, Sep. Purif. Technol. 26, 137 (2002)

2. P. Kaewsarn, Chemosphere 47, 1081 (2002)

3. M.I. Panayotova, Waste Management 21, 671 (2001)

4. R. Koivula, J. Lehto, L. Pajo, T. Gale, H. Leinonen, Hydrometallurgy 56, 93 (2000)

5. S.H. Lin, S.L. Lai, H.G. Leu, J. Hazard. Mater. 76, 139 (2000)

6. K.A. Matis, N.K. Lazaridis, A.I. Zouboulis, G.P. Gallios, V. Mavrov, J. Membr. Sci. 247, 29 (2005)

7. M.M. Matlock, B.S. Hoverton, D.A. Atwood, Water Res. 36, 4757 (2002).

8. R.M. Spearot, J.V. Peck, Environ. Progr. 3, 124 (1984)

9. O. Tunay, N.I. Kabdasli, Water Res. 28, 2117 (1994)

10. R-S. Juang, L-C. Lin, Water Res. 34, 43 (2000)

11. J. Lu, D.B. Dreisinger, W.C. Cooper, Hydrometallurgy 64, 1 (2002)

12. T.L. Hatfield, T.L. Kleven, D.T. Pierce, J. Appl. Electrochem. 26, 567 (1996)

13. L. Cifuentes, G. Crisostomo, J.P. Ibanez, J.M. Casas, F. Alvarez, G. Cifuentes, J. Membr. Sci. 207, 1 (2002)

14. D.E. Akretche, H. Kerdjoudj, C. Gavach, Hydrometallurgy 34, 231 (1993)

15. B. Schlichter, V. Mavrov, T. Erwe, H. Chmiel, J. Membr. Sci. 232, 99
(2004)

16. T. Mohammadi, A. Mohem, M. Sadrzadeh, A. Razmi, Desalination 169, 21 (2004)

17. X. Feng, J-s. Gao, Z-c. Wu, Zhejiang Univ. Sci. A 9, 1283 (2008)

18. M.J. Semmens, C.D. Dillon, C. Riley, Environ. Progr. 20, 251 (2001)

19. S.L. Vasilyuk, T.V. Maltseva, V.N. Belyakov, Desalination 162, 249 (2004)

20. P. Rana, N. Mohan, C. Rajagopal, Water Res. 38, 2811 (2004)

21. J.C. Farmer, S.M. Bahowick, J.E. Harrar, D.V. Fix, R.E. Martinelli, A.K. Vu, K.L. Carroll, Energy Fuels, 11, 337 (1997)

22. K. Dermentzis, Greek Patent GR1004819 (2005)

23. K. Dermentzis, Electrochim. Acta 53, 2953 (2008)

24. K. Dermentzis, K. Ouzounis, Electrochim. Acta 53, 7123 (2008)

25. K. Dermentzis, D. Papadopoulou, A. Christoforidis, A. Dermentzi, J. Eng. Sci. Technol. Rev. 2, 33 (2009)

26. B.H.Yao, D. Lian, J.D. Wu, 2002, Biomed. Eng., IEEE Transactions on 49, 277 (2002)

27. J.R. Mayell, Patent EP1840693 (2007)

28. E.M. Purcell, Electricity and Magnetism, Berkeley Physics Cource, Mc Graw-Hill, New York, vol. 2, p.80-89 (1965) 